\title{
Optimization of Maximum Power Point Tracking Flower Pollination Algorithm for a Standalone Solar Photovoltaic System
}

\author{
Muhammad Mateen Afzal Awan ${ }^{1 \mathrm{a}}$, Tahir Mahmood ${ }^{1 \mathrm{~b}}$
}

RECEIVED ON 18.10.2018, ACCEPTED ON 19.02.2019

\begin{abstract}
Modern-day world is facing problems such as, electricity generation deficiency, mounting energy demand, GHG (Greenhouse Gas) emissions, reliability and soaring prices. To resolve these issues, sustainable and renewable energy resources like SPV (Solar Photovoltaic) would be quite helpful. In this regard, the extraction of maximum power from SPV array in PSC (Partial Shading Weather Conditions) remains a challenge. Creation of multiple power peaks in the P-V (Power-Voltage) curve of a PV array due to partial shading, makes it difficult to track GMPP (Global Maximum Power Point) out of multiple power peaks known as LMPP (Local Maximum Power Points). Conventional algorithms are not able to perform in any condition other than UWC (Uniform Weather Condition). Nature inspired SC (Soft Computing) algorithms efficiently track the GMPP in PSC. The top performing SC algorithm named, FPA (Flower Pollination Algorithm) presents an efficient solution for GMPP tracking in PSCs. In this paper, the efficiency, accuracy and tracking speed of FPA algorithm is optimized. Comparison of the proposed OFPA (Optimized Flower Pollination Algorithm) and the existing FPAs is performed for zero shading condition, weak PSC, strong PSC, and changing weather conditions. In zero shading conditions, improvement of $0.7 \%$ in efficiency and $33 \%$ in tracking speed is achieved. In weak shading conditions, improvement of $0.97 \%$ in efficiency and $32.2 \%$ in tracking speed is achieved. In strong shading conditions, improvement of $0.24 \%$ in efficiency and $30.6 \%$ in tracking speed is achieved. OFPA is also tested for changing weather conditions (entering from Case-1 to Cae-3) and it retains its outstanding performance in the changing weather conditions. Simulations are performed in MATLAB/Simulink.
\end{abstract}

Key Words: Maximum Power Point Tracking, Global Maximum Power Point, Partial Shading Condition, Solar Photovoltaic.

\section{INTRODUCTION}

$\mathrm{M}$ odern energy generation technologies created huge problems for the world such as, pollution, respiratory diseases, GHG emissions, depletion of fuel resources etc. Renewable energy is a solution to produce clean energy generation [1]. Solar Photovoltaic can directly convert sunlight into electrical energy [2-3]. Efficiency of PV directly affects the cost of PV system, its payback time, price of energy generated from PV, area requirement for $\mathrm{PV}$ array, and energy savings. To make PV system efficient, it is necessary to operate PV array at its MPP (Maximum Power Point) to extract maximum power. For this purpose, MPPT (Maximum Power Point Tracker) are used [4]. MPPT is an electronic device, governed by algorithm.

In UWC all the cells of $\mathrm{PV}$ array receive same illumination. The P-V curve of PV array has one peak

\footnotetext{
${ }^{1}$ Department of Electrical Engineering, University of Engineering and Technology, Taxila, Pakistan

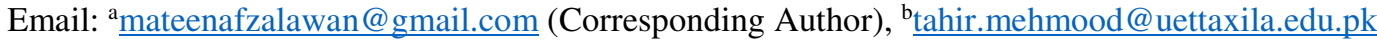


point known as MPP. Conventional MPPT algorithms successfully track the MPP in UWC. Conventional MPPT algorithms include: P\&O (Perturb and Observe) [5], InC (Incremental Conductance) [6], FSC (Fractional Short Circuit) [7] and FOC (Fractional Open Circuit) [8]. These algorithms efficiently track the MPP. The only drawback of conventional techniques in UWC is the steady state oscillations of OPP (Operating Power Point) around the MPP.

Partial shading is a condition when, all the cells or modules of PV array are receiving different illumination levels. Some area of PV array is shadowed due to any reason such as, birds dropping, buildings, trees, dust etc. In this condition the P-V curve of the PV array exhibits multiple power peaks known as LMPP (Local Maximum Power Points). The LMPP with the highest power is called GMPP. Tracking GMPP is a big challenge for trackers. Conventional algorithms fail to track GMPP in PSC [9]. Different improvements have been made but not satisfactory.

Improvements carried out in conventional MPPT algorithms like "Two Stage P\&O [10]" and "Direct Search MPPT [11]" techniques. In the first stage of "Two Stage P\&O technique", optimized zone is detected and in the second stage it locates the GMPP. In "Direct Search MPPT technique", the two-mode operation is conducted. Initially GMPP mode is activated and afterwards, switches to the other mode of conventional $\mathrm{P} \& \mathrm{O}$ method. Both improved methods are ineffective in PSC. To fill these drawbacks, researchers move towards the $\mathrm{SC}$ techniques.

In SC techniques, the ANN (Artificial Neural Network) [12], and the FL (Fuzzy Logic) [13], GA (Genetic Algorithm) [14], PSO (Particle Swarm Optimization) algorithm [15], DE (Differential Evolution) algorithm [16], RSM (Random Search Method) [17] and ABC (Artificial Bee Colony) algorithm [18] are the known ones. SC techniques performed better than the conventional techniques in tracking GMPP, but are complex, have high computation time and low convergence speed.

A new SC technique named FPA [19] has been devised by the scientific community, which performs much better than all the above mentioned conventional and soft computing techniques in UWC and PSC. [1921].

FPA has an advantage of having less number of parameters such as switching probability and scaling factor. Switching probability has been fixed at 0.8 , however, it does not ensure the fine balance between two types of searches. Such a drawback presents difficulty in GMPP tracking [22].

The rest of the paper is ordered as follows. Section-2 describes the modeling of SPV cell, section-3 explains the partial shading effects and FPA technique, section4 presents the problem formulation, section-5 describes the proposed optimized FPA algorithm", section-6 presents the simulation and results, section7 presents the conceptual comparison, section-8 performs the comparison, section-9 conclusion.

\section{MODELING OF SOLAR PHOTOVOLTAIC CELL}

One and Two diode models are the mostly used models of PV cell [23-24]. Despite of the greater accuracy of Two-diode model, mostly One-diode model is used because of its simplicity [25-26]. The One diode model of a PV cell is displayed in Fig. 1.

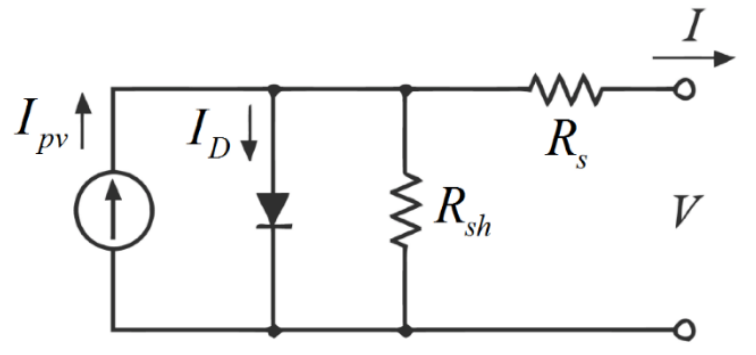

FIG 1: ONE DIODE MODEL OF PV CELL

Applying KCL at Fig. 1, the PV output current is:

$\mathrm{I}=\mathrm{I}_{\mathrm{PV}}-\mathrm{I}_{\mathrm{D}}-\left(\frac{\mathrm{V}+\mathrm{IRs}}{R_{s h}}\right)$

This single diode model has five parameters $\mathrm{I}_{\mathrm{pv}}, \mathrm{I}_{\mathrm{D}}, \mathrm{Rs}$, $\mathrm{R}_{\mathrm{sh}}$, and $\alpha$, where

$\mathrm{I}_{\mathrm{PV}}=$ current of $\mathrm{PV}$ cell,

$I_{D}=$ diode current, $R_{s}$ is resistance in series,

$\mathrm{R}_{\mathrm{sh}}=$ parallel resistance and

$\alpha=$ diode ideality factor. 
The diode current is calculated as

$\mathrm{I}_{\mathrm{D}}=\mathrm{I}_{0} \times\left[\exp \left(\frac{\mathrm{V}_{\mathrm{D}}}{\alpha \mathrm{V}_{\mathrm{T}}}\right)-1\right]$

where $V_{D}$ is Diode Voltage, $I_{0}$ is reverse saturation current. In the above equation $\mathrm{V}_{\mathrm{T}}$ is thermal voltage which is given by

$V_{T}=\frac{N_{S} k T}{q}$

where

$\mathrm{k}=$ Boltzmann Constant $=1.3805 \times 10^{-23}$,

Ns $=$ Number of series connected cells,

$\mathrm{T}$ is Temperature at STC (Standard Test Condition), \& $\mathrm{q}=$ Electron Charge $=1.9 \times 10^{-19} \mathrm{C}$.

The PV module's current can be calculated by:

$\mathrm{I}=\mathrm{N}_{\mathrm{pp}} \times\left(\mathrm{I}_{\mathrm{PV}}-\mathrm{I}_{0}\left[\exp \left(\frac{\mathrm{V}+\mathrm{IR}_{\mathrm{s}}}{\alpha \mathrm{V}_{\mathrm{T}} \mathrm{N}_{\mathrm{ss}}}\right)-1\right]-\left(\frac{\mathrm{V}+\mathrm{IR}_{\mathrm{s}}}{\mathrm{R}_{\mathrm{sh}}}\right)\right)$

\section{FLOWER POLLINATION ALGORITHM}

\subsection{Effects of Partial Shading Weather Conditions}

PV cells connect in parallel-series arrangement to form PV module and PV modules are connected in series to form PV array [27-28]. Under UWC, the P-V curve of PV array has one single MPP. But PSC creates multiple MPPs in the P-V curve, out of all those LMPP there is only one GMPP. Sources of partial shading can be, trees, constructions, smokes, moving clouds, bird dropping [29-30]. Array of four modules with different shaded patterns, no shading, weak partial shading and strong partial shading is revealed in Fig.2.

Bypass diodes are used to avoid "hotspots" [31], and blocking diodes are used to stop the "reverse current" [17]. Number of peaks depends upon the strength of shading. The P-V and I-V characteristic curves of PV array for the three cases (Case-1, Case-2, and Case-3) are displayed in the next sections of the paper.
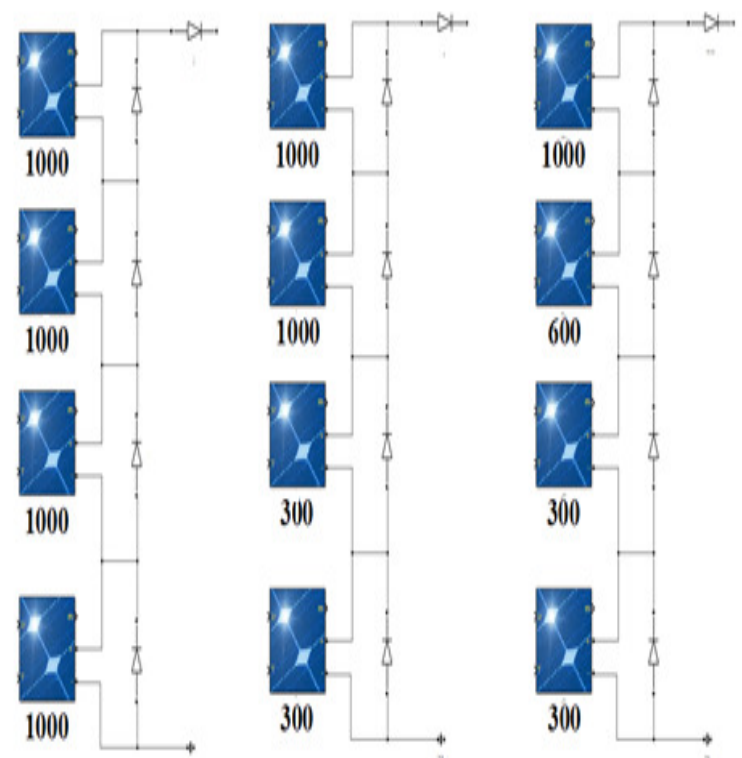

FIG. 2. ARRAY OF FOUR MODULES (4S) WITH SEPARATE TEST CASES CASE-1: NIL PARTIAL SHADING, CASE-2: WEAK PARTIAL SHADING, CASE-3: STRONG PARTIAL SHADING.

\subsection{FPA Algorithm}

FPA starts with the random generation of five pollens. These pollens are then send to the DC/DC converter to check amount of extracted power from the PV array against each sample. Pollen with the highest power is selected as a best pollen $\mathrm{P}_{\text {best. }}$. After completion of this first iteration, a random number is generated for each pollen and compared with the value of switching probability " $\mathrm{P}$ " (normally set at $\mathrm{P}=0.8$ ). If the randomly generated number is greater than the switching probability, pollen will go through the Local Pollination using Equation (7) else Global Pollination using Equation (8). The next set of new five pollens will be obtained after Local or Global pollination and then send to the DC/DC converter. After each iteration switching probability is compared with new random numbers for each pollen. The process repeats and at the end of each iteration one $\mathrm{P}_{\text {best }}$ is obtained. After twenty-five iterations, a set of $25 \mathrm{P}_{\text {best }}$ is obtained. $\mathrm{P}_{\text {best }}$ with highest power is selected as a Global Best "G $\mathrm{G}_{\text {best". }}$ ". Flowchart of the FPA is displayed in Fig. 3. Each step of FPA can be easily understood through Fig. 3 .

The GMPP changes with the change in weather, therefore detection of change in weather is obligatory.

Mehran University Research Journal of Engineering and Technology, Vol. 39, No. 2, April 2020 [p-ISSN: 0254-7821, e-ISSN: 2413-7219] 
This change is detected by the threshold values for the change in voltage $(\mathrm{dV})$ and change in current $(\mathrm{dI})$, set by the experimental trials and shown in Equations (56).

$$
\begin{aligned}
& \mathrm{dV}=\frac{\mathrm{V}_{\mathrm{PV}}(\mathrm{k})-\mathrm{V}_{\mathrm{PV}}(\mathrm{k}-1)}{\mathrm{V}_{\mathrm{PV}}(\mathrm{k})} \geq 0.2 \\
& \mathrm{dI}=\frac{\mathrm{I}_{\mathrm{PV}}(\mathrm{k})-\mathrm{I}_{\mathrm{PV}}(\mathrm{k}-1)}{\mathrm{I}_{\mathrm{PV}}(\mathrm{k})} \geq 0.1 \\
& \mathrm{X}_{\mathrm{i}}^{\mathrm{t}+1}=\mathrm{X}_{\mathrm{i}}^{\mathrm{t}}+\xi\left(\mathrm{X}_{\mathrm{k}}^{\mathrm{t}}-\mathrm{X}_{\mathrm{j}}^{\mathrm{t}}\right) \\
& \mathrm{X}_{\mathrm{i}}^{\mathrm{t}+1}=\mathrm{X}_{\mathrm{i}}^{\mathrm{t}}+\gamma \mathrm{L}(\lambda)\left(\mathrm{G}_{\text {best }}-\mathrm{X}_{\mathrm{i}}^{\mathrm{t}}\right)
\end{aligned}
$$

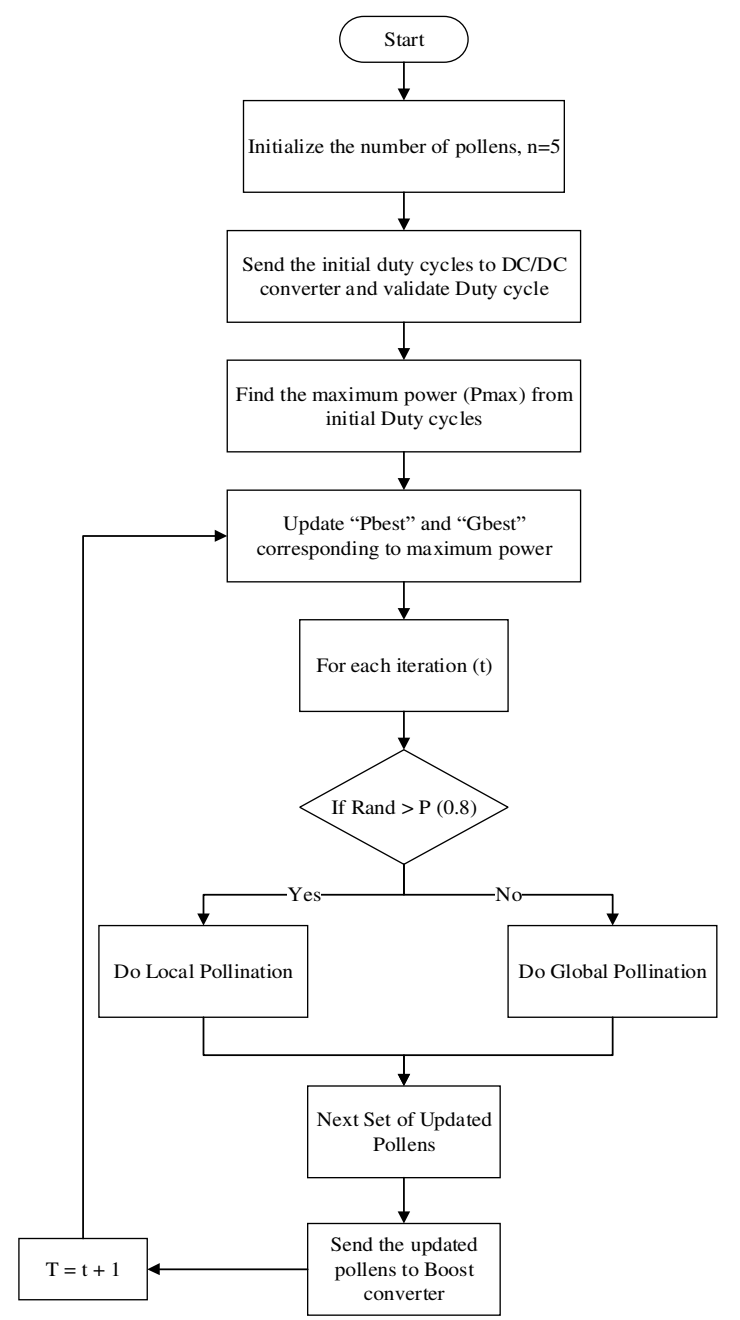

FIG. 3. FLOWCHART OF FPA ALGORITHM

$\mathrm{V}_{\mathrm{pv}}(\mathrm{k})$ is the voltage of a PV module at the $\mathrm{t}^{\text {th }}$ iteration and $\mathrm{V}_{\mathrm{pr}}(\mathrm{k}-1)$ is the voltage of a module at the preceding iteration. $\mathrm{I}_{\mathrm{pv}}(\mathrm{k})$ is the current of a PV module at the $\mathrm{t}^{\text {th }}$ iteration and $\mathrm{I}_{\mathrm{pv}}(\mathrm{k}-1)$ is the current of a PV module at the preceding iteration.

\section{PROBLEM FORMULATION}

FPA is an efficient technique but unfortunately not applied to PV system in an efficient manner. Problem is, that the PSC creates multiple power peaks in the P$\mathrm{V}$ curve of PV array and scanning of whole array is not possible because it will take much time. Different algorithms before FPA were applied such as PSO algorithm with almost same idea of randomness but were not much successful. The only reason which make FPA superior is improvement in randomness due to local and global pollination concept and use of levy flight in global pollination process. The advantage of global pollination is that; it improves randomness by throwing the random numbers at greater distance from each other. Utilizing this advantage in a proper way is desired. It is necessary to take steps for effective use of Global Pollination such as, reducing the value of switching probability "P" to increase the chance for pollens to start Local pollinating globally after going through the Global Pollination process. Keeping this in mind we are changing the FPA algorithm to utilize it in an efficient manner.

\section{PROPOSED OPTIMIZED FPA ALGORITHM}

In the proposed OFPA algorithm, the role of Global Pollination is efficiently utilized by introducing the concept of LCP (Local Cross Pollination). Initially five pollens are generated in the range of " $0-1$ ". These pollens are then send to DC/DC converter. Power against each pollen is calculated. Pollen with the highest power is selected as pollen best " $\mathrm{P}_{\text {best }}$ ". This set of five pollens will first go through the Local Pollination using Equation (7) and then Global Pollination using Equation (8). Power is calculated for these two sets and the two more pollen bests " $P_{\text {best }}$ " are obtained.

Now the process of LCP will start. In this LCP process, the set of pollens received after Local Pollination will now go through the Global Pollination process and the set of pollens received after Global Pollination will go through the Local Pollination process. Two more set

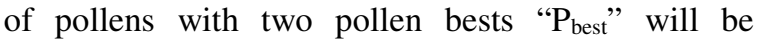
obtained at the end of LCP process. Five set of pollens with five " $P_{\text {best }}$ " are obtained.

Mehran University Research Journal of Engineering and Technology, Vol. 39, No. 2, April 2020 [p-ISSN: 0254-7821, e-ISSN: 2413-7219] 
Using the "Hit and Trial" method it is found that, the Switching probability " $P$ " equal to 0.2 provide the best results. A random number is generated and compared with switching probability for each pollen. If the "RN" is greater than "P", pollen will go through the Local Pollination else will go through the Global Pollination. Five set of pollens turns to Ten sets of pollens after this step with total Ten " $\mathrm{P}_{\text {best }}$ ".

Pollen best " $\mathrm{P}_{\text {best }}$ " from the Ten " $\mathrm{P}_{\text {best }}$ " with the highest power is selected as a Global best " $\mathrm{G}_{\text {best }}$ ". Flowchart of the proposed OFPA is presented in Fig. 4. Complete concept of the Optimized FPA is packed in Fig. 4.

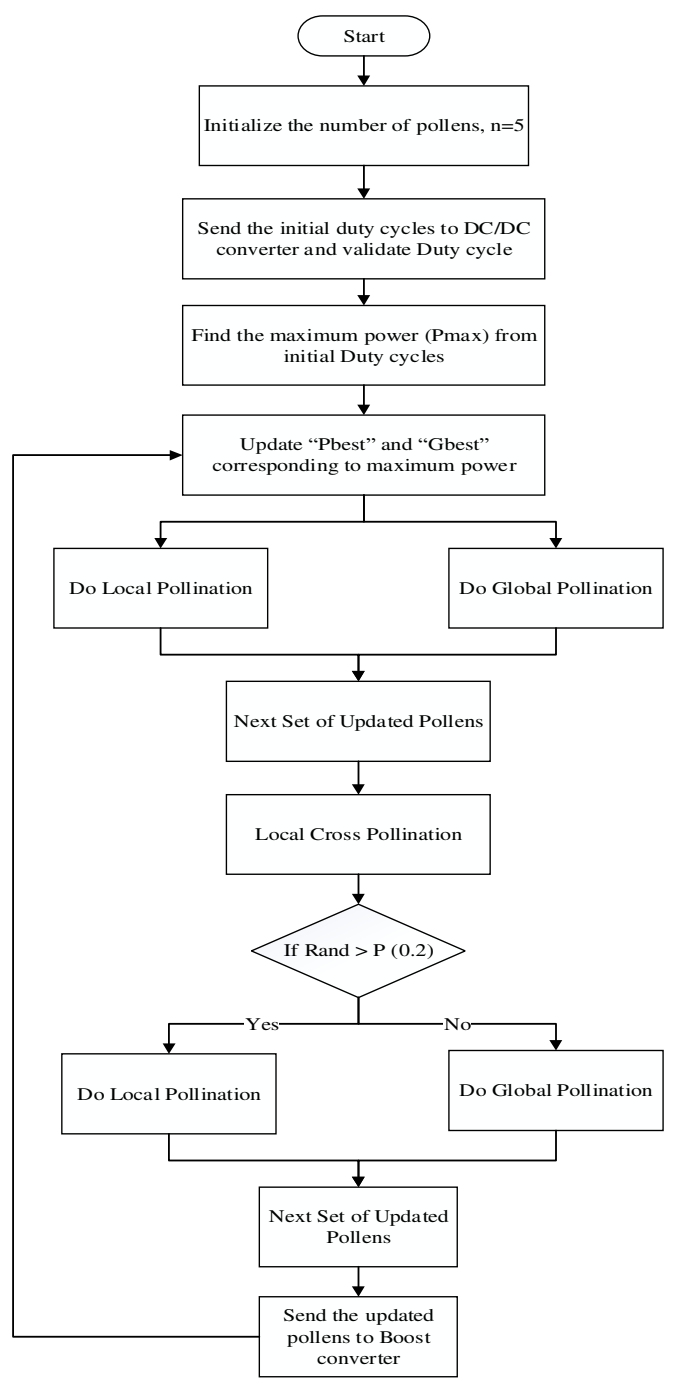

FIG. 4. FLOWCHART OF OPTIMIZED FLOWER POLLINATION ALGORITHM

\section{SIMULATION AND RESULTS}

Performance evaluation and comparison of OFPA with FPA is done in MATLAB/Simulink. Three different shading patterns discussed earlier in Case-1, Case-2 and Case-3, are used to verify the results. System configuration at which the algorithms are tested is, 64-bit Operating System, intel i3 Processor, and 4.00 GB RAM. Basic structure of the PV system with MPPT controller is displayed in Fig.5. PV module is connected to the DC-DC converter, which is controlled by MPPT and a DC-load is directly connected to the converter. The sample time among inputs (duty cycles) is set to 0.03 -seconds for FPA as mentioned in [20].

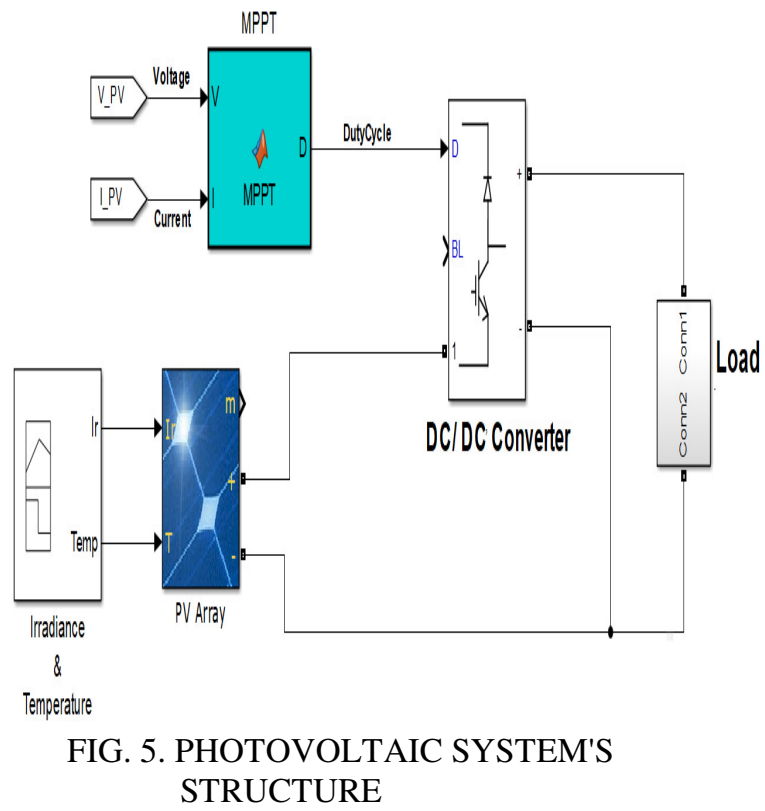

6.1 Case-1: Zero Shading

In this case, where all the PV modules are receiving same illumination, there is only one peak power point in the P-V curve. Achieving MPP here, is an easy task for FPA and the OFPA. The P-V and current-voltage "I-V" characteristic curves of PV array under this zero-shading condition is displayed in Fig. 6.

The values at MPP in a P-V characteristic curve, displayed in Fig. 6 are 40-Volts, 3-Amperes and "120Watt" respectively. The OFPA technique has achieved the target of " $120 \mathrm{~W}$ " with $100 \%$ efficiency and zero oscillations and FPA is successful in

Mehran University Research Journal of Engineering and Technology, Vol. 39, No. 2, April 2020 [p-ISSN: 0254-7821, e-ISSN: 2413-7219] 
extracting "119.2W" with the efficiency of $99.33 \%$ and without oscillations.

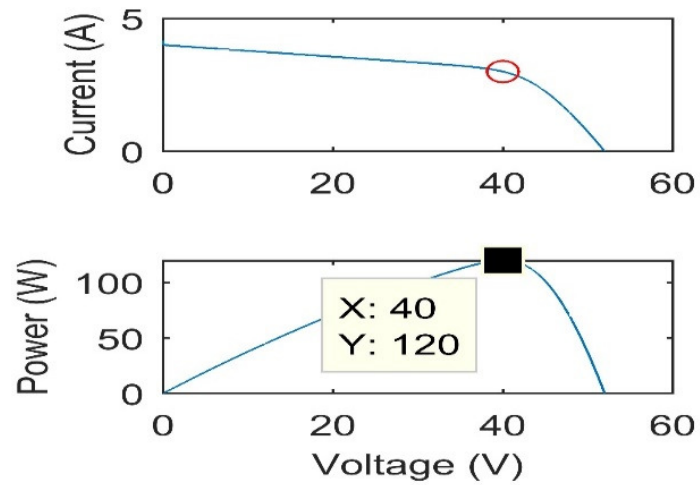

FIG. 6. GLOBAL I-V \&P-V CHARACTERISTICS OF A PV ARRAY IN ZERO SHADING CONDITION

The extracted power and MPP tracking time of FPA and the OFPA are "119.2W in 0.75-seconds", and " $120 \mathrm{~W}$ in 0.247 -seconds" respectively in a uniform or zero shading condition. It is evident from the results exposed in Fig. 7(a-b). that the OFPA outperforms the FPA in efficiency and accuracy. The OFPA algorithm has beaten the FPA algorithm in efficiency and tracking time in zero or uniform shading condition. The OFPA is $0.7 \%$ more efficient and $33 \%$ faster in tracking MPP than the FPA algorithm in zero or uniform shading condition.
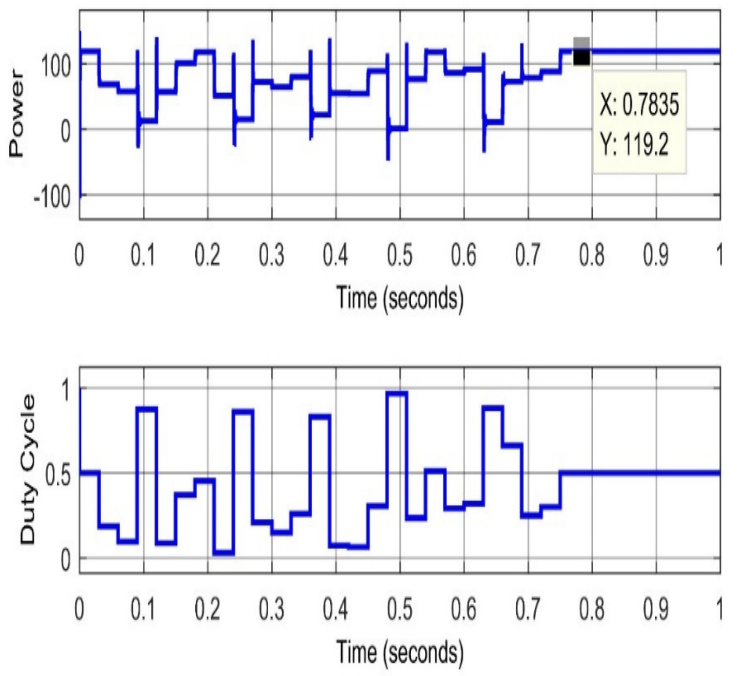

(a) FPA

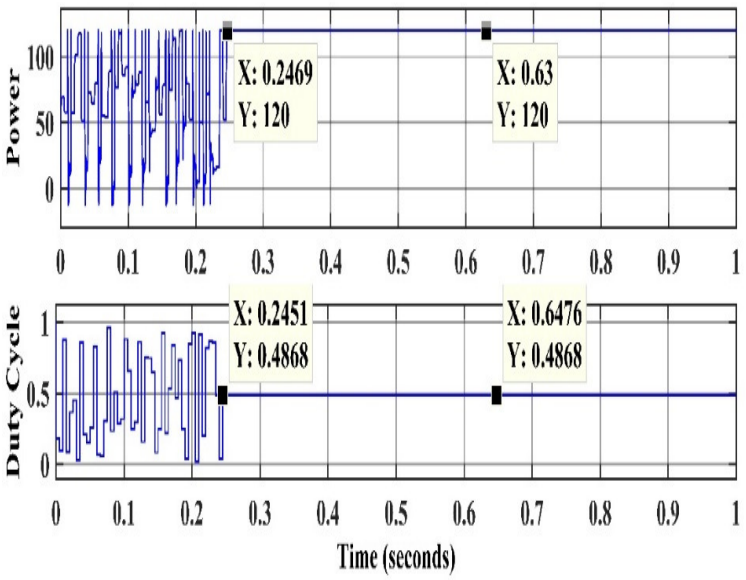

(b) OPTIMIZED FPA

FIG. 7. RESULTS OF FPA, AND OFPA ALGORITHM AT THE ZERO SHADING CONDITION.

\subsection{Case-2: Weak Partial Shading}

In case-2, weak partial shading is introduced. This creates two power peaks in the P-V curve of PV array. The P-V and I-V characteristic curves of a PV array for this case is displayed in Fig. 8.
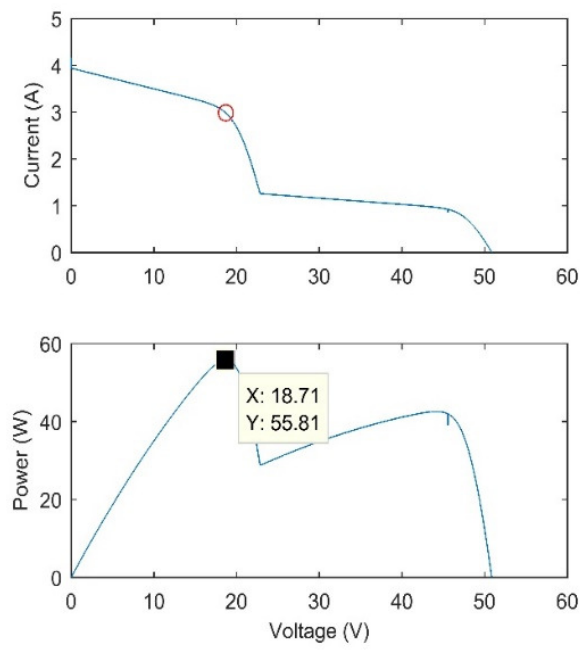

FIG. 8. GLOBAL I-V \&P-V CHARACTERISTICS OF PV ARRAY IN WEAK PARTIAL SHADING CONDITION

The values of the three variables voltage (V), current (I) and power (P) at MPP in a P-V characteristic curve is displayed in Fig. 8 are 18.71-Volts, 2.983-Amperes and 55.81Watt respectively. 
The extracted power and tracking time of FPA and OFPA algorithms are "55.25W in 0.78 -seconds", and " $55.78 \mathrm{~W}$ in 0.251 -seconds" respectively, in weak partial shading condition. It is evident from the results revealed in Fig. 9(a-b) that, in weak partial shading condition the OFP out performs the FPA in efficiency and accuracy. The OFPA algorithm has beaten the FPA algorithm in efficiency and tracking time in weak shading condition. The OFPA is $0.97 \%$ more efficient and $32.2 \%$ faster in tracking GMPP than the FPA algorithm in zero or uniform shading condition.
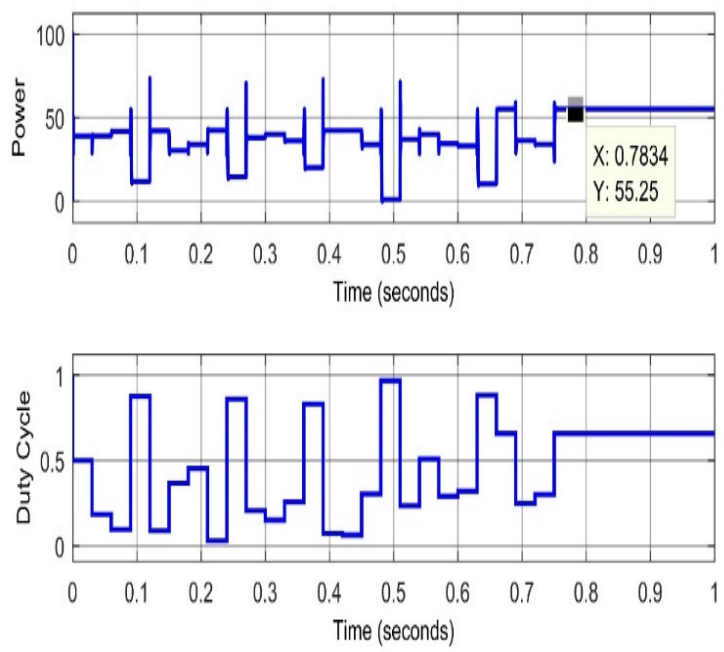

(A) FPA
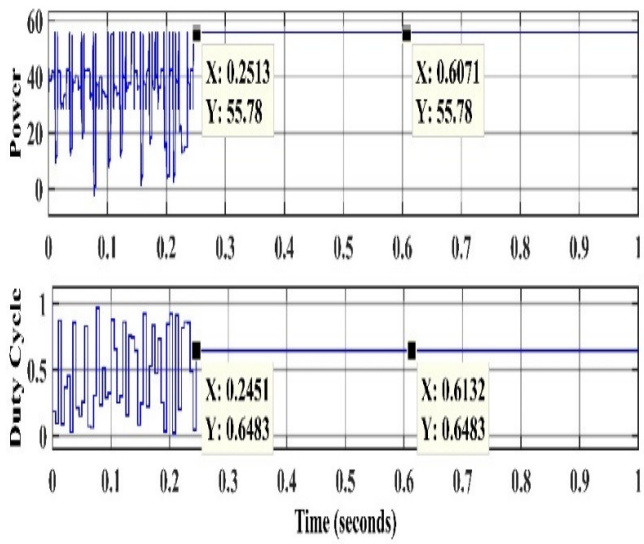

(B) OPTIMIZED FPA(TRACKING TIME AND POWER) FIG. 9. RESULTS OF FPA AND PROPOSEDOPTIMIZED FPA ALGORITHM AT WEAK SHADING CONDITION.

\subsection{Case-3: Strong Shading}

In case-3, Strong partial shading is applied to PV array. This creates three power peaks in the P-V curve. The P-V and I-V characteristic curves of a PV array under this strong SC is displayed in Fig. 10. It is very difficult to track the GMPP in this condition.
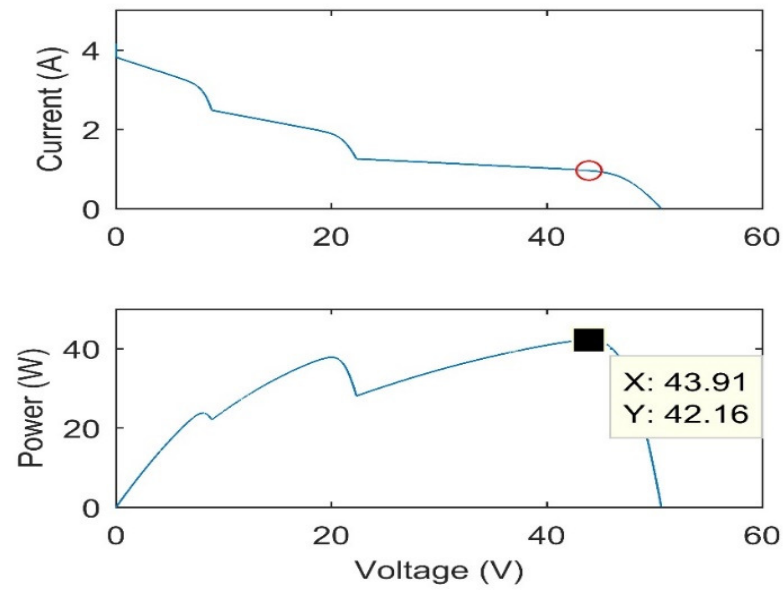

FIG. 10. GLOBAL I-V \&P-V CHARACTERISTICS OF PV ARRAY IN STRONG PARTIAL SHADING CONDITION

The values of the three variables voltage $(\mathrm{V})$, current (I) and power (P) at GMPP in a P-V characteristic curve displayed in Fig. 10 are 43.91-Volts, 0.96Amperes and 42.16-Watt respectively.

The extracted power and tracking time of FPA and OFPA are "42.05W in 0.79 -seconds", and " $42.15 \mathrm{~W}$ in 0.242-seconds" respectively, in strong partial shading condition. It is evident from the results presented in Fig.11(a-b) that the OFPA out performs the FPA in efficiency and accuracy in strong partial shading condition. The OFPA algorithm has beaten the FPA algorithm in efficiency and tracking time in strong shading condition. The OFPA is $0.24 \%$ more efficient and $30.6 \%$ faster in tracking GMPP than the FPA algorithm in zero or uniform shading condition.
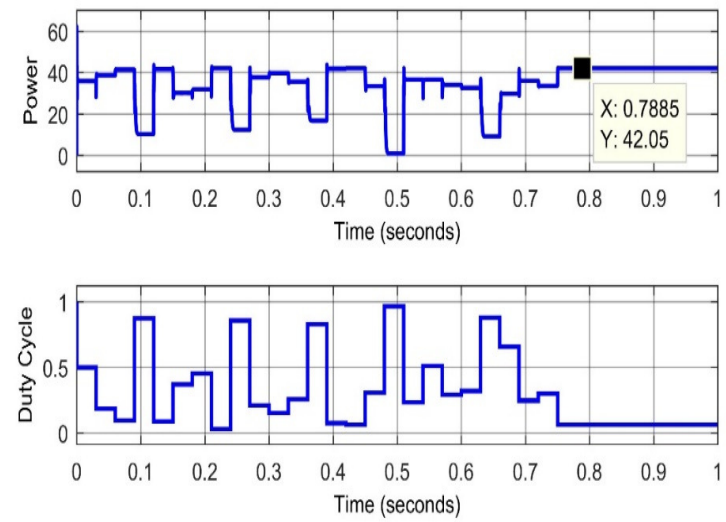

A) FPA

Mehran University Research Journal of Engineering and Technology, Vol. 39, No. 2, April 2020 [p-ISSN: 0254-7821, e-ISSN: 2413-7219] 
FIG. 11: RESULTS OF FPA AND PR
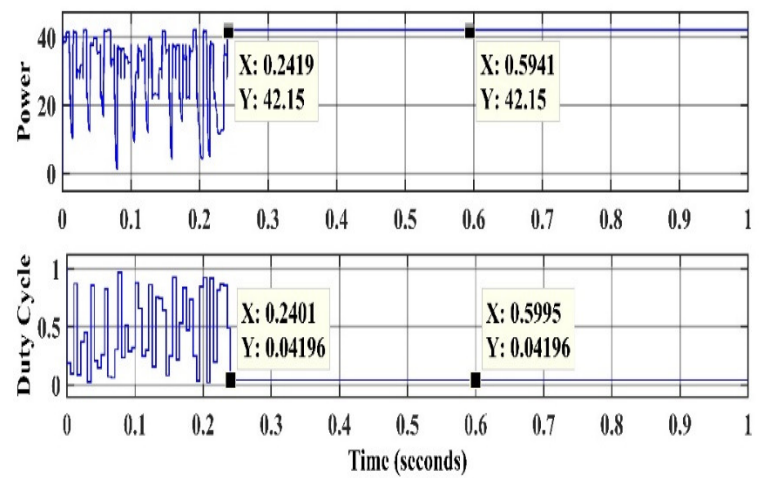

E) OPTIMIZED FPA (TRACKING POWER CONFIRMATION) FIG. 11. RESULTS OF FPA AND PROPOSEDOPTIMIZED FPA ALGORITHM AT STRONG SHADING CONDITION.

\section{CONCEPTUAL VIEW OF FPA AND THE OFPA ALGORITHM}

Conceptually the FPA and the OFPA can be compared at the following benchmarks, presented in the Table 1.

\begin{tabular}{|c|c|c|}
\hline \multicolumn{3}{|c|}{$\begin{array}{c}\text { TABLE 2. CONCEPTUAL COMPARISON OF } \\
\text { FPA AND OFPA ALGORITHMS }\end{array}$} \\
\hline Benchmarks & FPA & $\begin{array}{l}\text { Optimized } \\
\text { FPA }\end{array}$ \\
\hline $\begin{array}{l}\text { No. of Pollens } \\
\text { Generated }\end{array}$ & 125 & 50 \\
\hline $\begin{array}{l}\text { Switching } \\
\text { Probability }\end{array}$ & 0.8 & 0.2 \\
\hline $\begin{array}{c}\text { No. of Pollens } \\
\text { pass through } \\
\text { Global } \\
\text { Pollination }\end{array}$ & $\begin{array}{l}\text { Less than } \\
\text { Local }\end{array}$ & $\begin{array}{c}\text { Confirm }=10 \\
\text { Less than } \\
\text { Local (For last } \\
25 \text { pollens) }\end{array}$ \\
\hline $\begin{array}{c}\text { No. of Pollens } \\
\text { pass through } \\
\text { Local } \\
\text { Pollination }\end{array}$ & $\begin{array}{l}\text { More than } \\
\text { Global }\end{array}$ & $\begin{array}{c}\text { Confirm }=10 \\
\text { More than } \\
\text { Global (For } \\
\text { last } 25 \text { pollens) }\end{array}$ \\
\hline
\end{tabular}

It can be clearly seen in Table. 1, that the FPA is not utilizing the Local and Global Pollination in an efficient manner by providing a huge space $(80 \%)$ to Local pollination only, by using $\mathrm{P}=0.8$. Most of the pollens pass through Local Pollination in FPA and there is no balance between Local and Global Pollination. In the OFPA, Local and Global Pollination are balanced by passing minimum TEN pollens from each Pollination process. OFPA provide a chance to Local Pollination to search at Global positions for the remaining Twenty-Five pollens by setting $\mathrm{P}=0.2$.

\section{COMPARISON}

The results of FPA and OFPA for zero, partial weak and partial strong shadings are summarized in the Table 2. The Table 2. has summarized the performance evaluation of FPA and OFPA algorithms. It presents the comparison in terms of efficiency and tracking time for the three cases of partial shadings. The OFPA algorithm has proved it priority over FPA algorithm in efficiency and tracking time in three cases. Comparison results have proved OFPA algorithm a better choice for GMPP and MPP tracking under shading and non-shading conditions respectively.

\subsection{Analysis of OFPA Algorithm for Partial Shading}

The performance of OFPA has been checked for nil, weak and strong PSC separately. Performance test of OFPA undergoing case- 1 to case- 2 and then case- 3 together is also performed. Rise and fall in illumination due to different actions like clouds, birds fallen leaf etc. is considered and simulated. Results are presented in Fig. 12.

\begin{tabular}{|c|c|c|c|c|c|c|c|}
\hline \multicolumn{8}{|c|}{ TABLE 2. COMPARISON BETWEEN OFPA, AND FPA ALGORITHMS } \\
\hline $\begin{array}{l}\text { Shading } \\
\text { Patterns }\end{array}$ & Algorithms & $\begin{array}{l}\mathrm{P}_{\mathrm{MPP}} \\
(\mathrm{w})\end{array}$ & $\begin{array}{c}\text { Rated } \\
\text { Power } \\
\text { (W) }\end{array}$ & $\begin{array}{c}\text { Efficiency } \\
(\%)\end{array}$ & $\begin{array}{l}\text { Tracking } \\
\text { Time (Sec) }\end{array}$ & $\begin{array}{l}\text { Efficiency } \\
\text { Improvement } \\
\text { by OFPA }\end{array}$ & $\begin{array}{c}\text { Improvement } \\
\text { in Tracking } \\
\text { Time by } \\
\text { OFPA }\end{array}$ \\
\hline \multirow{2}{*}{ Case-1 } & OFPA & 120 & \multirow{2}{*}{120} & 100 & 0.247 & \multirow[b]{2}{*}{$0.7 \%$} & \multirow[b]{2}{*}{$33 \%$} \\
\hline & FPA & 119.2 & & 99.3 & 0.75 & & \\
\hline \multirow{2}{*}{ Case-2 } & OFPA & 55.78 & \multirow{2}{*}{55.81} & 99.95 & 0.251 & \multirow{2}{*}{$0.97 \%$} & \multirow{2}{*}{$32.2 \%$} \\
\hline & FPA & 55.25 & & 98.99 & 0.78 & & \\
\hline \multirow{2}{*}{ Case-3 } & OFPA & 42.15 & \multirow{2}{*}{42.16} & 99.98 & 0.242 & \multirow{2}{*}{$0.24 \%$} & \multirow{2}{*}{$30.6 \%$} \\
\hline & FPA & 42.05 & & 99.74 & 0.79 & & \\
\hline
\end{tabular}



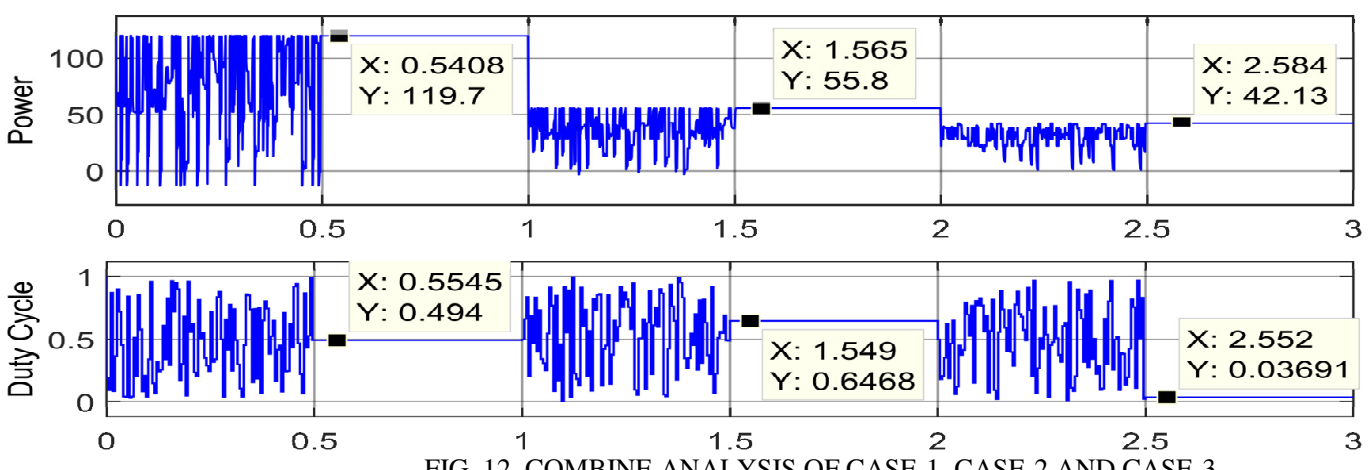

FIG. 12. COMBINE ANALYSIS OF CASE-1, CASE-2 AND CASE-3

Success story of OFPA can be clearly in Fig. 12. It starts with zero partial shading (Case-1), after 1-sec the PV array undergoes weak partial shading (Case-2), and after 2-sec the PV array experience strong partial shading condition (Case-3). In all three cases OFPA retains its performance in terms of GMPP tracking accuracy and efficiency. It proves that it can easily handle the change in weather conditions. It detects the change in weather (illumination or temperature) by observing the change in power output of PV array. It does not need any illumination or temperature sensors which also reduces the cost of PV system. Entering from zero shading to weak and from weak to strong partial shading could not affects the accuracy, efficiency and speed of OFPA algorithm in tracking GMPP. Performance analysis of OFPA undergoing three cases is summarized in Table 3.

\begin{tabular}{|c|c|c|c|}
\hline \multicolumn{4}{|c|}{ TABLE 3.PERFORMANCE ANALYSIS OF } \\
OPTIMIZED FPAALGORITHM UNDERGOING \\
THREE CASES \\
\hline Cases & $\begin{array}{c}\text { PMPP } \\
\text { (W) }\end{array}$ & $\begin{array}{c}\text { Rated } \\
\text { Power } \\
(\mathrm{W})\end{array}$ & $\begin{array}{c}\text { Efficiency } \\
(\%)\end{array}$ \\
\hline 1 & 119.7 & 120 & 99.75 \\
\hline 2 & 55.8 & 55.81 & 99.98 \\
\hline 3 & 42.13 & 42.16 & 99.93 \\
\hline
\end{tabular}

\section{CONCLUSION}

An optimized FPA algorithm is Proposed for GMPP tracking in PSC. Various cases of zero shading, uniform shading, weak partial shading and strong partial shading are simulated and compared. The results have proved that, the optimized FPA algorithm performs better than the FPA algorithm in all shading and non-shading weather conditions. In the proposed “Optimized Flower Pollination” (OFPA) algorithm, the role of Global Pollination is efficiently utilized by introducing the concept of Local Cross Pollination (LCP). Additionally, the switching probability is set to “ 0.2 " to optimize the role of local pollination process in tracking GMPP, to get efficient results. Optimized FPA is more efficient and accurate than the FPA algorithm. The optimized FPA algorithm successfully, efficiently and accurately achieved GMPP in record time in all weather conditions (zero shading, uniform shading, weak partial shading and strong partial shading).

\section{ACKNOWLEDGMENT}

The authors would like to thank the Department of Electrical Engineering, University of Engineering \& Technology Taxila, Pakistan, for supporting the work and specially Malik Sher Afzal Awan, for improving the quality of work with their valuable suggestions.

\section{REFERENCES}

[1] Awan, M.M.A., and Awan, F.G., "Improvement of Maximum Power Point Tracking Perturb and Observe Algorithm for a Standalone Solar Photovoltaic System", Mehran University 
Research Journal of Engineering \& Technology, Volume 36, No 3, pp. 501-510, Jamshoro, Pakistan, July, 2017.

[2] Kamran, M., Bilal, M., and Zaib, Z.J., "LabVIEW Based Simulator for Solar Cell Characteristics and MPPT Under Varying Atmospheric Conditions", Mehran University Research Journal of Engineering \& Technology, Volume 37, No. 3, pp. 529538, Jamshoro, Pakistan, July, 2018.

[3] Kamran, M., Bilal, M., and Mudassar, M., "DC Home Appliances for DC Distribution System", Mehran University Research Journal of Engineering \& Technology, Volume 36, No 4, pp. 881-890, Jamshoro, Pakistan, October, 2017.

[4] Ghasemi, M.A., Ramyar, A., and Iman-Eini, H., "MPPT Method for PV Systems Under Partially Shaded Conditions by Approximating I-V Curve", IEEE Transactions on Industrial Electronics, Volume 65, No. 5, pp. 3966-3975, May, 2018.

[5] Ahmed, J., Salam, Z., "An Enhanced Adaptive P\&O MPPT for Fast and Efficient Tracking Under Varying Environmental Conditions", Volume 9, No 3, pp. 1487 - 1496, January, 2018.

[6] Safari, A., and Mekhilef, S., "Simulation and Hardware Implementation of Incremental Conductance MPPT with Direct Control Method Using Cuk Converter", IEEE Transactions on Industrial Electronics, Volume 58, No 4, pp. 1154-1161, April, 2011.

[7] Sher, H.A., Murtaza, A.F., Noman, A., Addoweesh, K.E., Al-Haddad, K., and
Chiaberge, M., “A New Sensor less Hybrid MPPT Algorithm Based on Fractional ShortCircuit Current Measurement and $\mathrm{P} \& \mathrm{O}$ MPPT", IEEE Transactions on Sustainable Energy, Volume 6, No 4, pp. 1426-1434, October, 2015.

[8] Shebani, M.M., Iqbal, T., and Quaicoe, J.E., "Comparing Bisection Numerical Algorithm with Fractional Short Circuit Current and Open Circuit Voltage Methods for MPPT Photovoltaic Systems", IEEE Conference on Electrical Power and Energy, pp. 1-5, 2016.

[9] Ram, J.P., Babu, T.S., and Rajasekar, N., “A Comprehensive Review on Solar PV Maximum Power Point Tracking Techniques", Renewable Sustainable Energy Reviews, Volume67, pp. 826-47, January, 2017.

[10] Femia, N., Petrone, G., Spagnuolo, G., and Vitelli, M., "A Technique for Improving P\&O MPPT Performances of Double-Stage Grid-Connected Photovoltaic Systems", IEEE Transactions on Industrial Electronics, Volume 56, No. 11, pp. 3456-3467, November, 2009.

[11] Nguyen, T.L., and Low, K.S., "A Global Maximum Power Point Tracking Scheme Employing DIRECT Search Algorithm for Photovoltaic Systems", IEEE Transaction on Industrial Electronics, Volume 57, No. 10, pp. 4473-4482, September, 2010.

[12] Syafaruddin, Karatepe, E., and Hiyama, T., "Artificial Neural Network-Polar Coordinated Fuzzy Controller Based Maximum Power Point Tracking Control under Partially Shaded Conditions", IET 
Renewable Power Generation, Volume 3, No. 2, pp. 239-253, May, 2009.

[13] Tang, S., Sun, Y., Chen, Y., Zhao, Y., Yang, Y., and Szeto, W., "An Enhanced MPPT Method Combining Fractional-Order and Fuzzy Logic Control", IEEE Journal of Photovoltaics, Volume 7 , No. 2, pp. 640$650,2017$.

[14] Lee, C., Tsou, H., Chou, T., and Weng, K., "Application of the Hybrid Taguchi Genetic Algorithm to Maximum Power Point Tracking of Photovoltaic System", IEEE International Conference on Applied System Invention, pp. 231-234, 2018.

[15] Li, H., Yang, D., Su, W., Lu, J., and Yu, X., "An Overall Distribution Particle Swarm Optimization MPPT Algorithm for Photovoltaic System Under Partial Shading”, IEEE Transactions on Industrial Electronics, Volume 66, No. 1, pp. 265-275, January, 2019.

[16] Tajuddin, M.F.N., Ayob, S.M., and Salam, Z., "Global Maximum Power Point Tracking of PV System Using Dynamic Population Size Differential Evolution Algorithm”, IEEE Conference on Energy Conversion, pp. 254-259, October, 2014.

[17] Sundareswaran, K., Peddapati, S., and Palani, S., "Application of Random Search Method for Maximum Power Point Tracking in Partially Shaded Photovoltaic Systems", IET Renewable Power Generation, Volume 8, No. 6, pp. 670-678, August, 2014.

[18] Kinattingal, S., Peddapati, S., Nayak, P.S.R., Sishaj, S.P., and Sankaran, P., "Enhanced Energy Output From a PV System Under Partial Shaded Conditions
Through Artificial Bee Colony", IEEE Transactions on Sustainable Energy, Volume 6, No. 1, pp.198-209, 2015.

[19] Ram, J.P., and Rajasekar, N., “A New Global Maximum Power Point Tracking Technique for Solar Photovoltaic (PV) System under Partial Shading Conditions (PSC)", Energy, pp. 1-14, October, 2016.

[20] Ram, J.P., and Rajasekar, N., "A Novel Flower Pollination Based Global Maximum Power Point Method for Solar Maximum Power Point Tracking”, IEEE Transactions on Power Electronics, Volume 32, No. 11, pp. 8486-8499, November, 2017.

[21] Awan, M. M. A., and Mahmood, T., "A Novel Ten Check Maximum Power Point Tracking Algorithm for a Standalone Solar Photovoltaic System”, Electronics, Volume 7, Issue 11, pp. 327, November, 2018.

[22] Lukasik, S., and Kowalski, P.A., "Study of Flower Pollination Algorithm for Continuous Optimization”, Intelligent Systems' 2014”, Advances in Intelligent Systems and Computing-Springer, Volume 322, pp. 451459, 2015.

[23] Koad, R.B.A., Zobaa, A.F., and El-Shahat, A., "A Novel MPPT Algorithm Based on Particle Swarm Optimization for Photovoltaic Systems", IEEE Transactions on Sustainable Energy, Volume 8, No. 2, pp. 468-476, April, 2017.

[24] Shongwe, S., and Hanif, M., "Comparative Analysis of Different Single-Diode PV Modeling Methods", IEEE Journal of Photovoltaic, Volume 5, No. 3, pp. 938-946, May, 2015. 
[25] Rajasekar, N., Neeraja, K., and Venugopalan, R., "Bacterial Foraging Algorithm Based Solar PV Parameter Estimation", Solar Energy, Volume 97, pp. 255-265, November, 2013.

[26] Koran, A., La-Bella, T., and Lai, J., "High Efficiency Photovoltaic Source Simulator with Fast Response Time for Solar Power Conditioning Systems Evaluation", IEEE Transactions on Power Electronic, Volume. 29, No. 3, pp. 1285-1296, March, 2014.

[27] Niranjan, D.S., Bhaskar, D.S., Shekar, M.J., Sudhakar, B.T., and Rajasekar, N., "Solar PV Array Reconfiguration under Partial Shading Conditions for Maximum Power Extraction

Using Genetic Algorithm”, Renewable Sustainable Energy Review, Volume 43, pp. 102-110, March, 2015.
[28] Rani, B.I., Ilango, G.S., and Nagamani, C., "Enhanced Power Generation from PV Array under Partial Shading Conditions by Shade Dispersion Using Su Do Ku Configuration”, IEEE Transactions on Sustainable Energy, Volume 4, No. 3, pp. 594-601, July, 2013.

[29] Ishaque, K., and Salam, Z., “A Deterministic Particle Swarm Optimization Maximum Power Point Tracker for Photovoltaic System under Partial Shading Condition", IEEE Transactions on Industrial Electronic, Volume 60, No. 8, pp. 3195-3206, August, 2013. 